\title{
UMA CRÍTICA À TEORIA DA COMPLEXIDADE PROPOSTA POR EDGAR MORIN.
}

\author{
Érico Andrade \\ Universidade Federal de Alagoas
}

\begin{abstract}
The aim of our article is restricted to the proposition of a critic of the theory of the complexity theory. The critic is about his ontological presupposition: complex reality to demand a complexity science. This critic try to point the problems of this theory, marked by a strong metaphysical appeal, when it intends to establish knowledge a priori. On the other hand, our critical analysis tries to deconstruct part of the arguments of the complexity theory addressed to the generalization of some complex models - developed in some branches of the scientific knowledge - while subterfuge for the constitution of a general theory of the science. So, to we defend the idea of when it does not retake presupposition of the metaphysical tradition - the ontology determines the epistemology: myth of given - the complexity theory fails in determining the modus operandis of the science from a metascientific theory that is experimentally impracticable.
\end{abstract}

Keywords: Ontology, method, complexity, Descartes, Morin.

Resumo: 0 escopo de nosso artigo restringe-se à proposição de uma crítica à teoria da complexidade quanto ao seu pressuposto ontológico: realidade complexa e à inalação decorrente de tal pressuposto; a necessidade de uma ciência da complexidade. Essa crítica visa apontar, por um lado, as insuficiências da referida teoria, marcada por um forte apelo metafísico, quando essa pretende estabelecer um conhecimento a priori e inédito apoiado supostamente num dado empírico ou mais precisamente na complexidade do real. Por outro, nossa crítica tenta desconstruir parte dos argumentos da teoria da complexidade voltados à generalização de certos modelo complexos - empreendidos em alguns ramos do saber científico - enquanto subterfúgio para a constituição de uma teoria geral da ciência. Assim, defendermos a idéia de que quando não retoma pressuposto da tradição metafísica - a ontologia determina a epistemologia; já invalidados porque recorrem ao mythy of given - a teoria da complexidade incorre na grave falhe de determinar o modus operandis da ciência a partir de uma teoria metacientífica, inexeqüível experimentalmente.

Palavras chaves: Ontologia, método, complexidade, Descartes, Morin. 


\section{Introdução}

O campo epistemológico é hoje atravessado por problemáticas bem diversas. Por um lado, multiplicam-se artigos voltados ao desenvolvimento de epistemologias regionais que se ocupam de pressupostos e de métodos das ciências particulares: filosofia da química, filosofia da biologia, filosofia da física, etc. Por outro lado, as contribuições ulteriores acerca da crise dos fundamentos da física clássica e da matemática ramificam-se em formas diversas - crítica pragmática das proposições científicas e reconhecimento do caráter histórico da ciência, considerada menos como um acúmulo nos dizeres de Kant; de juízos sintéticos a priori que pela sua função de fomento à paradigmas historicamente incomensuráveis - mineralizando uma concepção fragmentária da ciência cuja epistemologia resultante termina refém da impossibilidade da constituição de um saber universal. A ciência e epistemologia contemporâneas igualam-se no prognóstico concernente à certeza da impossibilidade de um saber a priori e universal; alheio a toda forma de revisão teórica.

A dimensão que a referida crise alcança não será incólumes às tentativas de reinstaurar uma ciência sistêmica capaz de reunir a diversidade dos saberes sob a forma de um único método. Se os caminhos para o projeto da modernidade de matematizar as ciências, inscrevendo-as numa física geral, ou ainda as tentativa relativamente recentes do Círculo de Viena de constituir uma ciência unificada, essencialmente aparada no conhecimento físico (empírico) e fundamentada num sistema axiomático e lógico (formal), foram alvos de críticas contumazes; a única saída para uma refundação epistêmica da unidade das ciências parece implicar por um lado, um reconhecimento da especificidade inegociável de cada ciência. Por outro, a assimilação de uma unidade, ainda que instável das ciências. Essa dupla condição subscreve exigências aparentemente contraditórias e inconciliáveis.

Entretanto, a análise e discussão, realizada nas últimas décadas do século XX, de fenômenos considerados complexos fornecera um novo ânimo à epistemologia no que concerne, sobretudo, à constituição do método científico. Esses fenômenos fogem ao padrão normalmente aceito pela ciência, pois concorrem para sua compreensão as diversas contribuições das ciências particulares, sem que a diferença estrutural que elas possuem seja 
escamoteada em favor de um discurso adstrito de simplificação do saber. A interface das ciências estaria disposta numa forma paradoxal que inclui diversidade e multiplicidade metodológica como critério cardinal para explicação de certos fenômenos naturais.

Desse modo, a fronteira metodológica que atravessara a ciência fragmentado-a em campos antagônicos do saber - começa a ser transgredida dada a complexidade de algumas modelações do natural cuja aplicação aparenta requerer uma nova roupagem metodológica. Todavia, esse parecer não é unânime entre os teóricos da ciência. Diante desse debate, que toma diferentes feições na literatura filosófica, nosso artigo inscreve-se numa tentativa de dissuadir a necessidade, defendida por Edgar Morin, da constituição uma teoria da complexidade como resposta às insuficiências da ciência tradicional. Em outras palavras, pretendemos inquirir e apontar os limites - se existentes - da teoria da complexidade no tocante à constituição de uma ciência alternativa àquela concebida pelo modelo, para usarmos as palavras de Morin, tradicional.

Nossa tarefa neste artigo se limitará a uma discussão que comporta três etapas. 1 Apresentação de alguns fenômenos complexos 2 Discussão de algumas teses e argumentos seminais da teoria da complexidade 3 Crítica da teoria da complexidade, subdividida em: a) crítica ao pressuposto ontológica da referida teoria; b) Crítica pragmática da possibilidade de uma saber universal. Concluiremos que a teoria da complexidade têm dificuldades estruturais - porque inscritas nos limites epistemológicos da fundação de uma ciência unificada - em justificar o seu pressuposto ontológico: a realidade complexa e em explicar a passagem dos modelos complexos para uma ciência da complexidade. A função do nosso artigo não é de propor uma teoria alternativa àquela da complexidade, mas ele consiste apenas em apontar as insuficiências da referida teoria.

\section{Fenômenos Complexos}

Parte das ciências contemporâneas depara-se hoje com fenômenos que não são redutíveis às categorias convencionais e normalmente aceitas na prática científica, tais como a causalidade - linearidade do tempo - ou a ordem - pressuposto que todos os fenômenos indicam um estado de objetos ligados em função de um padrão dinâmico, invariavelmente determinado. Por isso, dissemina-se em diversas áreas a necessidade de constituir um 
método que leve em consideração a desordem - caos - não como a transcrição de um empecilho à explicação do real, mas como elemento significativo no que tange à compreensão de fenômenos cujo tecido cristaliza interações que escapam à estrutura causal da ciência clássica.

Desse modo, fenômenos para cuja caracterização demandava-se um entendimento de uma certa noção de caos, não são mais tratados como bastardos em relação aos seus, agora, homônimos, abordados pelo modelo tradicional, pois considerar certos fenômenos em função da desordem que lhes gera não parece ser mais a confirmação de sua incogniscibilidade. Ao contrário, a natureza caótica dessa sorte de fenômenos transgride os padrões clássicos de compreensão, mas não acarreta a instalação de um limite epistemológico à ciência. Os diferentes domínios do saber científico operam com a incerteza e com a aparente irracionalidade de alguns fenômenos sem perderem, contudo, a possibilidade de licenciarem a construção de novas tecnologias.

A meteorologia é um exemplo lapidar dessa nova compreensão da atividade científica. Os fenômenos meteorológicos não obedecem a padrões lineares conforme os quais se poderia determinar, num longo prazo, por exemplo, a previsibilidade de certas precipitações. Ao contrário das previsões de eclipses solares cujo o longo intervalo de tempo de suas ocorrências não é obstáculo à sua predição, realizada através do instrumental da física newtoniana, fenômenos meteorológicos comportam padrões aleatórios, os quais reduzem a sua previsibilidade à semanas. Em outras palavras, as previsões meteorológicas não valem para períodos extremamente longos, porque mínimas imprecisões nos dados estabelecidos nas condições iniciais, essencialmente instáveis porque condicionados à inúmeras e imprevisíveis variáveis, geram divergências exponenciais ao longo do tempo.

Por conseguinte, há uma dificuldade estrutural para a instituição de hipóteses ad hoc, pois não se trata de desprezar certas variáveis ou de explicálas em função de uma adaptação dos pressupostos teóricos às lacunas eventuais que emergem na teoria. O limite é estrutural porque a meteorologia reconhece-se incapaz de fornecer pareceres seguros diante da aleatoridade dos fenômenos climáticos. Ela limita, portanto, definitivamente a escala de tempo com a qual trabalha a fim de tonar menos espessa a imprevisibilidade daqueles fenômenos.

Ainda que esses fenômenos não sejam subordinados a um comportamento linear, sendo submetidos à variáveis descontínuas no tempo; 
é possível predizê-los em função do cálculo de fractais que rescreve a sua aleatoridade através de uma análise matemática das relações e interações que suas possíveis variáveis - balanços energéticos, balanços hídricos e de circulação de correntes oceânicas e atmosféricas - podem realizar em um curto intervalo. De onde se segue que para o avanço na medição de elementos como temperatura e pressão, responsáveis pela variação térmica da atmosfera, faz-se necessário aplicar o cálculo de fractais, que descreve situações caóticas, ao comportamento aleatório dos fenômenos climáticos. A partir dessas considerações pode-se ultrapassar, por um lado, as barreiras impostas pela concepção clássica da ciência, que exigiria da meteorologia última uma explicação determinística, por isso precisa e alheia aos próprios limites dessa ciência. Por outro, pode-se subsidiar simulações climáticas mais próximas de predições rigorosas graças ao reconhecimento da aleatoridade dos referidos fenômenos.

Semelhante à meteorologia tem-se na economia os trabalhos de Hayke. Neles encontramos a afirmação que a particularidade dos fenômenos complexos, em contraposição aos fenômenos simples em economia, concentrar-se-ia em pelo menos dois pontos principais: $1 \mathrm{Em}$ primeiro lugar pelo grande número de variáveis distintas, conectadas entre si, que se fariam necessárias para a formulação matemática de problemas relativos às redes de agentes econômicos a serem investigadas. 2 Além disso, nosso acesso a essas variáveis é problemático, no sentido de que não estaríamos aptos a assegurar, via observação, a presença de todos os elementos necessários que compõem nossos sistemas dedutivos. Isto é, não estaríamos aptos a substituir por constantes numéricas todas as variáveis relevantes nos modelos econômicos. Desse modo, a determinabilidade, ainda que por aproximação, de certos fenômenos econômicos não poderia ser alcançada - dada a forte dependência das condições iniciais cuja dinâmica não-linear impossibilita previsões senão através da substituição da análise e das tentativas improfícuas de previsões de fenômenos particulares pelo estudo de ocorrência de classes de fenômenos que se influenciam e interagem entre si recursivamente. Em outras palavras, Hayek sustenta que se deve desviar o interesse da predição de eventos particulares (típicos das teorias tradicionais, segundo ele) para outros tipos de teorias, dedicadas exclusivamente à explicação e à previsão de padrões de ocorrência de fenômenos complexos cujo comportamento não pode ser concebido de maneira particular, mas a partir da inter-relação - 
incompletas e por vezes contraditórias - entre as várias classes de fenômenos discretos ou particulares, produzidos pelos agentes econômicos.

A complexidade garimpa também espaços na biologia acometendo a sua principal teoria, a saber a teoria da evolução na medida em que lhe imputa lacunas irremediáveis. A teoria da evolução que fora concebida por Darwin de forma linear: com variações temporais contínuas e teologicamente voltadas a melhor adaptação das espécies ao meio; será criticada e revista. Segundo os modelos de complexidade atuais, empreendidos na biologia, a evolução das espécies torna-se imprevisível e pode divergir de forma exponencial quanto às etapas "seguidas" por cada espécie. Assim, a biologia trabalha com o caráter probabilístico do comportamento de um grande número de componentes: disposição orgânica instável e ambígua de alguns seres vivos, sobretudo os virus, a bifurcação de variáveis imprevissíveis como as condições climáticas, as influências do meio ambiente com a espécie (que não são totalmente conhecidas) e a impossibilidade de prever plenamente a reação de organismos vivos, sobretudo sua interação com o ambiente no percurso do tempo. Esse conjunto de variáveis escasseiam as pretensões de se constituir um desenvolvimento da teoria da evolução sem que seja levada em consideração o caráter aleatório de parte dos fenômenos biológicos que operam a transformação ou metamorfose das espécies.

Desse modo, as ciência diferenciam-se quanto aos seus objetos e igualam-se na complexidade dos seus modelos. Conquanto, a profusão de fenômenos complexos parece subverter as fronteiras das ciências na medida em que os diferentes domínios do saber passam a comungar de informações comuns e inequivocamente essenciais acerca de fenômenos que eram aparentemente incomunicáveis. A rede que afigura a realidade fomenta um tecido de múltiplas variáveis para cuja saturação concorrem ciências distintas e complementares. Notadamente nos fenômenos que envolvem as áreas abordadas operam combinações e contribuições de diferentes domínios: a meteorologia deve levar em consideração a dinâmica da economia que dita o ritmo da poluição e alterações climáticas, a biologia deve levar em consideração os agentes climáticos como fatores importantes na relação do homem com o meio, os atores econômicos condicionam investimentos à estabilidade climática e aos recursos hídricos de certas regiões, etc. Desse modo, a interdisciplinaridade parece ser nesses casos um imperativo para compreensão dos fenômenos complexos, visto a rede de relações que eles 
formam, perpetra um intercâmbio de informações que não pode ser obliterado.

Do ponto de vista metacientífico os referidos fenômenos trazem conseqüências aparentemente desconcertantes para a epistemologia, diríamos em "migalhas", considerando que para compreensão de parte deles parece ser inevitável a emergência de uma ciência senão unificada ao menos sem rígidos limites que as separem. De sorte que nos parece pertinente perguntarmos se os fenômenos complexos demandam uma teoria da complexidade ou ainda uma epistemologia da complexidade.

\section{A resposta da Teoria da Complexidade segundo Morin}

Se para compreensão de certos fenômenos naturais concorrem diversas ciências que aportam contribuições distintas e complementares, a explicação de vários outros fenômenos resta ainda longe de ganhar uma roupagem interdisciplinar. Com efeito, no intuito de prover as ciências de um novo paradigma, capaz de abarcar os fenômenos complexos, a teoria da complexidade emerge como uma tentativa de estender a interpretação e modelação dos referidos fenômenos à compreensão total da natureza. Em outros termos, costura-se uma nova aliança entre as ciências como uma forma de se opor ao modelo epistemológico tradicional - marcado pela impossibilidade epistemológica e lógica (teorema de Gödel) de se transcrever os enunciados ditos fundamentais ou nos dizeres de Carnap; protocolares sob a forma de uma rede de conexões lógicas de proposições elementares constituindo, em virtude desta nova aliança, uma ciência da complexidade cujo epicentro repousa por um lado na assimilação da diversidade e complexidade como eixo estrutural da compreensão da natureza. Por outro, na constituição de uma ciência unificada porque apoiada na combinação das diversas contribuições científicas.

Convém, segundo a teoria da complexidade, por um lado, retraçar a ligação entre as ciências a fim de não mais sujeitá-las à divisão aguda e dilacerante da tradicional epistemologia. Por outro, dever-se-ia requerer uma investidura unificadora que não destitui-se - de forma disjuntiva - a especificidade dos métodos científicos, isto é, dever-se-ia procurar a conjunção entre as ciências, sem constrangê-las a uma redução de suas especificidades; realizada pelo modelo epistemológico tradicional que galgado na simplificação dos objetos das diferentes ciências reteve-as apenas naquilo 
que revela da matemática. Vejamos agora alguns argumentos da teoria da complexidade.

Um dos argumentos centrais da teoria da complexidade, proposta por Morin, subscreve a complexidade do real como um limite à visão simplificadora e abstrata da matéria como extensão, instituída por Descartes. Em outras palavras, os fenômenos complexos, ditam o fim da tentativa moderna, sobretudo aquela de cunho iminentemente cartesiano, de constituir uma ciência capaz de determinar seu objeto segundo a simplificação ontológica do mundo. Assim, o pensamento cartesiano, bem como seus subseqüentes desenvolvimentos, padeceria de uma miopia congênita inapta a visualizar a complexidade do natural. Escreve Morin:

A complexidade não está à margem do fenômeno real. Ela é o seu princípio mesmo. O fundamento físico daquilo que nós chamamos realidade não é simples, mas complexo ${ }^{1}$.

Da natureza emana uma complexidade que é aderente à estrutura do fenômenos naturais enquanto condição para sua inteligibilidade. A complexidade é tomada, por Morin, como o constituto da realidade em dissonância face à matéria amorfa cartesiana - redutora porque estritamente geométrica e profundamente simples porque alheia à íntima relação entre os diversos e aleatórios fenômenos naturais .

Considerando a estrutura ontológica da natureza - essencialmente complexa -, a ciência não poderia ser constituída sob a rejeição do complexo, refugiando-se em ilogismos senão alheios ao mundo, pouco próximos do real. Escreve Morin:

A associação complementar onda/partícula não se originou de um ilogismo do pensamento, mas de um ilogismo da realidade, levando a pensar que alguns aspectos da realidade microfísica não obedecem à lógica dedutiva-indentitária (Morin, 1998, p.227).

Dilui-se as pretensões de instituir um discurso simplificador do real sem a compreensão da dualidade inscrita na própria estrutura da matéria,

\footnotetext{
1 La complexité n'est pas à l'écume phénoménale du réel. Elle est à son principe même. Le fondement physique de ce que nous appelons réalité n'est pas simple, mais complexe. Morin, 1990, p. 251
} 
abrindo-se margem, por conseguinte, à instauração de uma ciência que acolha a dualidade como seu elemento constituinte. Passa-se de um ontologia anfíbia que transita entre matéria e energia para uma teoria da complexidade, que está imbuída da pretensão de apresentar a lógica interna do real sob a lente da complexo.

Segue-se da teoria da complexidade uma crítica à armadura formal matemática - do mundo que o reduzira a engrenagens solidamente equacionáveis. O método cartesiano, que seria a raiz de ulteriores reduções da ciência à matemática, é particularmente objetado por sua ineficácia no que tange à explicação da passagem dos fenômenos físicos aos fenômenos orgânicos. Desse modo, o desafio imposto pela segunda lei da termodinâmica (que prescreve que se um processo físico ocorre em um sistema fechado, a entropia do sistema aumenta para irreversíveis processos e permanece constante para reversíveis processos, sem nunca diminuir) à biologia, para qual os sistemas vivos se auto-organizam constantemente, escaparia ao paradigma cartesiano da ciência que, por um lado, é essencialmente quantitativo por isso dissimétrico em relação a um olhar qualitativo, exigido pela biologia. Por outro, trata-se de um paradigma que menospreza à nãolinearidadde e incerteza de alguns fenômenos, essenciais à ciência contemporânea.

Por conseqüência, exigir-se-ia, em virtude da passagem do inorgânico para o orgânico o surgimento de um pensamento complexo. Pensamento este dotado do poder de aglutinar - sem excluir - as diferentes contribuições da ciência, moldando uma visão sistêmica do natural cujo arcabouço seria capaz de explicar, entre outras coisas, a passagem do inorgânico para o orgânico, mediante o diálogo entre a biologia e a física.

O paradigma cartesiano, que restringira a análise do real às variações determináveis quantitativamente - de fragmentos da res extensa, deveria ser substituído, segundo Morin, por sua ineficiência no que concerne à compreensão da complexidade do real, sobretudo, naquilo que revela da passagem do físico para o orgânico. Assim, subseqüente à diluição da realidade simples em diversos extratos de um tecido complexo, Morin desprende-se da ontologia, segundo sua denominação, simplificadora cartesiana, no intuito de avançar a recuperação daquilo que a modernidade 
teria jogado no lixo: a reemergência dos seres ${ }^{2}$. Essa reemergência dos seres só poderia ser adquirida mediante a eliminação do entendimento da realidade como uma oposição inconciliável entre qualidade e quantidade, instituindo-se, a partir das ruínas do paradigma cartesiano, uma teoria da complexidade enquanto tentativa de coalizão entre a ordem (vida/qualidade) e a desordem (lei da entropia/física/quantidade), visto que entre o equilíbrio e o desequilíbrio move-se a vida e, por conseguinte, a ciência deverá transitar entre um sistema fechado (dinâmico-físico) e aberto (biológico). Em uma palavra, a ciência é um sistema ambíguo (cf. Morin, 2003, p.23).

Nesta perspectiva, as considerações de Morin imprimem uma inexorabilidade da construção de uma ciência da complexidade e, ainda mais radicalmente, uma epistemologia da complexidade, tomada como o único e último subterfúgio para se evadir dos limites do projeto e pensamento modernos. Em razão desse novo paradigma da complexidade poder-se-ia fabricar uma explicação qualitativa do real, a despeito da racionalização fria cartesiana, ancorada em três princípios: recursividade, hologromático e dialógico.

Morin propõe a subtração das diferenças, que divorciam os saberes ciências, em favor de um sistema não disjuntivo no qual o diálogo princípio dialógico - entre as ciências pode tornar evidente como os fenômenos se auto constituem em sua interação e inter-relações, reassimilando-os no tecido complexo do real. Ademais, a consciência que a recursividade de certos fenômenos - conforme a qual há uma indistinção entre os princípios de causa e efeito, dada a íntima ligação e recíproca constituição que eles guardam entre si no que tange os fenômenos complexos - não pode apontar para outra coisa senão para a necessidade de uma ciência que ao invés de pressupor a divisão entre efeito e causa, concebe os fenômenos em suas múltiplas e aleatórias influências, provendo-lhes de uma explicação unitária e holística. Por fim, a teoria da complexidade espelha-se na biologia no intenção de reter dela o princípio hologromático, para o qual, segundo a interpretação de Morin, o todo é indissociado da partes e as parte detém o todo: as células são mecanismos que portam todas as informações relevantes do organismos vivos e a compreensão daquilo que é vivo

2 Desse modo sua tarefa [teoria da complexidade] consistiria também em conduzir-nos a um necessário refundamento conceptual; operar a reemergência dos seres, dos indivíduos lançada no lixo pela ciência clássica. Morin, E e Le Moigne, 2000, p.135. 
estabelece-se na combinação das vária moléculas que se auto-organizam enquanto um sistema orgânico (cf. Morin, 2003, p.52).

Precisa-se, para se compreender como as ciências se comunicam e comungam informações acerca de fenômenos aparentemente distintos porque tratados por ciências distintas - uma epistemologia não menos complexa que comporte os princípios da teoria da complexidade: recursividade, hologromático e dialógico. Essa é a conclusão de Morin:

Toda introdução da contradição e da incerteza pode transforma-se em ganho de complexidade; é nesse sentido que a limitação trazida pela física quântica ao conhecimento determinista/mecanicista se transforma em ampliação complexificadora do conhecimento e adquire um sentido plenamente epsitemológico (Morin, 1998, p.236-237).

O aumento de complexidade do natural conduz inevitavelmente a uma epsitemologia da complexidade. Em outras palavras, para abranger o orgânico (biológico: auto-organizador e auto-regulador) e o físico (incerto e caótico), abrigando-os numa nova aliança, seria necessário, diríamos, escamotear a ontologia simplificadora e a ciência decorrente dela, não menos redutora, e avançar a instauração de uma nova epistemologia: sistêmica e aberta. Conciliar a ordem e o caos é o imperativo que se põe à epistemologia, porque nessa conciliação repousa, segundo Morin, o próprio natural e o seu espelho, a ciência. Só uma epistemologia da complexidade poderia reconduzir as ciências para um fundamento, ainda que esse fundamento não seja a assimilação de um modelo de explicação absoluta e unificadora, mas uma fonte inesgotável de incerteza (cf. Morin, 2003, p.22).

\section{Problemas e pressupostos da teoria da complexidade}

O pressuposto que uma certa ontologia subsidia uma epistemologia é antigo. Encontramos esse pressuposto seja no pensamento aristotélico, para quem o mundo ordenado (Cosmos) e dividido conforme os genus entis requer uma teoria da ciência que a tipifique segundo uma hierarquia ou 
divisão dos seus objetos ${ }^{3}$; seja para Hegel, que resgata no mundo uma dinâmica, diríamos, dialética cuja ciência resultante aponta para uma teoria qualitativa da natureza como resposta à ciência quantitativa newtoniana restrita, segundo Hegel, porque essencialmente matemática e, porquanto, improfícua no que concerne à explicação sistêmica do universo ou de sua onto-teo-logia ${ }^{4}$. Poder-se-ia afirmar em linhas gerais que para esse filósofos a metafísica financiara fortemente a epistemologia das ciências, condicionandoa não apenas à análise das condições formais e empíricas do conhecimento, mas estendo-a à compreensão da razão que constitui a qualidade e organização do universo.

Entretanto, da ontologia à epsitemologia nem sempre há um caminho linear. A assertiva de Morin quanto à relação entre epistemologia e ontologia parece negligenciar esse fato e centra-se no seguinte raciocínio: se há uma ontologia (realidade) "complexa" deve haver igualmente uma ciência da complexidade que tem como conseqüência uma epistemologia complexa. Essa proposição prescreve o seguinte pressuposto: conteúdos não epistêmicos do conhecimento podem constituir uma ciência e, subseqüentemente, uma epistemologia. Em outras palavras, a realidade constrange a ciência a adotar uma linha de pesquisa.

Além desse pressuposto ontológico, a teoria da complexidade encerra ainda um outro pressuposto concernente à necessidade de instauração de uma ciência da complexidade como ponto de coalizão de alguns modelos complexos, perpetrados por ramos específicos do saber. Ou seja, dever-se-ia, face a um contingente importante de modelos complexos, empreendidos na compreensão de determinados fenômenos, instituir uma ciência da complexidade, fazendo com que a complexidade de alguns modelos teóricos seja um imperativo à instalação de uma ciência da complexidade e ainda mais radicalmente de uma epistemologia da complexidade.

O primeiro pressuposto está no âmbito da ontologia, confundido-se, contudo, com a epistemologia no que tange a possibilidade de se instituir um discurso sobre o real. $O$ segundo pressuposto encerra uma discussão

\footnotetext{
3 Isso era o que ocorria em Aristóteles por exemplo, para quem " ... la chose même [qui] leur fit un chemin (hodopoiesen) et les contraingnit à la recherche ». Aristote. Métaphysique. Trad. Trico, J. Paris, Vrin, 1991. (A, 3, 984 a 18-19,).

${ }^{4} \mathrm{~A}$ explicação da passagem do quantitativo para o qualitativo fora o objeto central da análise hegeliana da natureza que não contribuiu com a ciência senão de forma negativa, apresentando a certeza de que eliminar os dados empíricos a favor da imaginação pode no máximo ajudar a construir bons romances sobre a natureza, mas jamais explicações exeqüíveis experimentalmente.
} 
iminentemente epistemológica conforme a qual põe-se em discussão a relação entre o método científico e a ciência. Considerando essa divisão, elencaremos inicialmente alguns problemas da teoria da complexidade relativos à sua recorrência, para usarmos a expressão de Sellears, ao myth of given, apontando para os elos que a referida teoria mantém com a tradição metafísica (Cf. Sellears, 1997, p.33). No que concerne ao segundo pressuposto, denominado por nós epistemológico, procuraremos recuperar o ponto de continuidade que une a teoria da complexidade com a tradicional epistemologia, no intuito de apresentar, a partir de uma visão pragmática, as dificuldades de se instituir um método universal para as ciências; pressuposto igualmente presente na teoria da complexidade e no projeto cartesiano. Com essas considerações [(a) ontológicas e (b) epistemológica] acreditamos que será possível apontar as insuficiências da referida teoria.

a) A crítica ao pressuposto, aceito sem grandes restrições pela teoria da complexidade, que o mundo fornece o dado à ciência remonta a Hume. Se os intérpretes de Hume dividem-se, quanto à dimensão que seu ceticismo alcança - para uns pode-se creditar ao pensamento humeano as raízes fundamentais do cepticismo moderno, ao passo que para outros, esse cepticismo poderia ser atenuado face ao naturalismo, implícito na obra de Hume, que permitiria um certo conhecimento do real - eles convergem em relação ao ponto de inflexão que Hume introduz na epistemologia: a crítica ao racionalismo (cf. Smith, 1995, p.72).

Segundo Hume, a justificação do conhecimento não passaria mais pela legitimação da ontologia, instaurada por uma certa metafísica racionalista, mas pelo distanciamento dessa em relação à epistemologia, dado os limites estruturais da ciência no que concerne à representatividade das sensações. $\mathrm{Ou}$ seja, a tarefa da epistemologia deveria ser essencialmente negativa no que se refere à fundamentação ontológica do conhecimento, visto que ela consiste em apontar o abismo estrutural e intransponível que opõe as sensações às idéias que as representam.

A argumentação de Hume centra-se em dois pontos. Primeiro ele sustenta que as idéias ditas complexas (como aquelas da metafísica tradicional) são redutíveis à idéias simples que transcreveriam um certo número de sensações singulares cuja generalização fora apropriada indevidamente pela metafísica. Segundo, todas as idéias estão condicionadas às sensações que lhes desencadearam, sendo a privação dos sentidos um empecilho irremediável à compreensão de certas idéias. A exceção das idéias 
de razão (matemática e lógica), Hume sustenta uma dupla implicação ou ainda uma correspondência bionívoca entre as idéias e as sensações, inviabilizando qualquer forma de discurso a priori como maneira de instituir uma metafísica do natural, dada a impossibilidade da idéia ter uma outra raiz que não seja aquela aderida às sensações particulares. $O$ discurso metafísico seria, em última instância, um uso inadvertido de certas idéias (como a de "bom”, "justo", etc.) as quais seriam generalizadas sem que fosse apresentada a sensação que lhe corresponderia (cf. Hume, 1973, p.135).

Contra uma razão absorta e ilimitada, Hume restitui a mente humana enquanto ponto nevrálgico do conhecimento - no sentido humeano a epistemologia resvala numa psicologia do conhecimento em oposição à fundamentação ontológica do conhecimento mediante a razão pura - na intenção de suprimir a certeza meta-empírica do racionalismo, através da qual se poderia desvelar a natureza a partir de proposições a priori. Como conseqüência dessa perspectiva psicologista, imputa-se a linearidade dos fenômenos naturais ao âmbito da crença moral, hábito, inscritos na mente humana. Assim, Hume consagra a mente como sustentáculo da associação de idéias 5 . O mundo passa a ser considerado a totalidade dos fatos - da causalidade que projetamos sobre os fenômenos - e não das coisas. Nesse sentido, a anatomia da mente revela a estrutura do conhecimento, mas não a natureza do real.

A psicologização do conhecimento empreendida por Hume é a primeira tentativa de livrar a epistemologia da submissão à ontologia. No entanto, ela revela-se num certo sentido dogmática, por incorrer no erro, comum ao racionalismo e a própria teoria da complexidade, de se creditar à sensação a possibilidade de fornecer informações brutas sobre o real. Nesse sentido, o trabalho dos filósofos contemporâneos, estranhamente obliterados por Morin, radicalizam a distância entre a ontologia, mediada por um discurso metafísico, e a epistemologia.

Ainda que imbuída da necessidade de fornecer uma alternativa à ontologia cartesiana, a teoria da complexidade proposta por Morin faz ressurgir o ímpeto metafísico de procurar no natural o caminho da pesquisa na medida em que ela propõe um direcionamento da ciência à compreensão da essência complexa do real. Se o pensamento de Hume ainda padecera de

${ }^{5} 0$ termo moral deve ser entendido em oposição ao termo demonstração racional, pois não se trata da moral enquanto objeto da ética, mas dos costumes que temos de acreditar que certos efeitos têm uma determinada causa. Cf. Hume, 1973, p.142. 
uma certa ingenuidade, concernente à assimilação da sensação como a fonte dos dados científicos, a vertente mais contemporânea do empirismo dilui a pretensão de instituir como um dado uma sensação bruta, sob a alegação que esse mito pressupõe dogmaticamente que se poderia tomar uma informação na natureza sem que essa última estivesse previamente enquadrada numa rede conceptual. Tal postura teórica, nos ensina Sellars, alimenta-se do falso pressuposto que o conhecimento não-inferencial oferece os dados - myth of given - necessários ao conjunto de ulteriores inferências e abordagem científicas.

A teoria da complexidade incorre no myth of given na medida em ela pressupõe que o mundo ou mais precisamente o dado é o guia de toda abordagem científica - trata-se de um pressuposto, considerando que não há justificativas senão aquelas iminentemente circulares: o mundo é complexo, porque ele se apresenta de forma complexa, ele se apresenta de forma complexa porque é complexo. Em outras palavras, observações particulares de fenômenos complexos transcreveriam para a teoria da complexidade o fato inquestionável porque dado sem qualquer mediação teórica; por isso evidente - de que o mundo é complexo, visto que essas observações comportariam fenômenos inéditos que exigiriam, por seu turno, uma teoria não menos inédita. Sob esse prisma, o mundo carregaria consigo os segredos íntimos de uma estrutura ontológica, para nos determos especificamente à as palavras de Morin; complexa para cuja compreensão seria necessário uma teoria inédita sobre o real.

Desse modo, a teoria da complexidade abstém-se de compreender a proposição científica como elemento veinculador de significação que aponta sempre para um contexto conceptual. Ela não percebe que sem a mediação de uma teoria a proposição científica não porta nenhum significado, ou seja, uma proposição científica não pode se referir isoladamente a um fato ou dado no mundo em função do qual poder-se-ia corroborá-la ou falsificá-la e posteriormente enquadrá-la nua teoria. Todas assertivas sobre o "real" pressupõem e estão submersas numa linguagem ou numa rede conceitos de sorte que elas não fazem sentido senão quando a pensamos num sistema de proposições articuladas. Assim, por exemplo, não faz sentido que se procure na natureza, mediante a experiência, a fórmula da água $(\mathrm{H} 2 \mathrm{O})$ sem o domínio prévio da notação e das propriedades dos elementos estruturais da química, visto que o conhecimento da linguagem científica, empreendida para a caracterização dos diversos fenômenos, é fundamental para que se 
compreenda as proposições científicas singulares, relativas a um determinado fenômeno, como a composição química da água. Ou seja, a significatividade de uma proposição científica é costurada muita mais a partir da rede proposições em que ela se encontra que numa eventual contato com o real ${ }^{6}$.

Portanto, a teoria da complexidade apresenta o mesmo "erro" cartesiano no tocante à compreensão do objeto como um dado extralingüístico sob a alegação de que ao se conceber a realidade como um complexo de ordem/desordem poder-se-ia oferecer uma alternativa à ontologia cartesiana (ordem); esquecendo, porém, que o grande problema epistemológico, relativo ao discurso metafísico de maneira geral, consiste na impossibilidade de apreensão do real em sua quididade - seja ela complexa ou simples - dado os limites concernentes ao pressuposto de se ter acesso a um dado sem uma linguagem prévia que lhe confere um significado. De modo mais incisivo, poderíamos dizer, então, que a teoria da complexidade ao conceber o conceito de complexidade sem os ilogismos da razão pretende defender a idéia de que é possível conhecer sem conceituar, pois o dado impunha - imprimiria? - no indivíduo o conceito de complexidade e, conseqüentemente, a necessidade do pensamento complexo, o qual deveria se instituir a partir de uma linguagem própria e inédita em conformidade com a complexidade que emana do real.

Convém notar que menos que um dado absoluto, fiador de teorias inéditas, a ontologia científica parece ser, nas palavras de Quine, um mito mais conveniente segundo uma rede de conceitos e axiomas ${ }^{7}$. A ciência requer uma certa ontologia e não o contrário, pois, senão, estaríamos dizendo que algo que não é pensável (conteúdo não-inferencial) determinaria o pensamento, particularmente o modo de proceder da ciência. O que implicaria a separação, criticada por Morin, porém retomada por ele mesmo; entre objeto e pensamento, tomados como esferas distintas e independentes na constituição da ciência.

b) Considerando que algumas observações modelam fenômenos que não podem ser descritos em função de padrões dinâmicos - determináveis

\footnotetext{
${ }^{6}$ Deve-se notar que as teorias científicas não tocam a experiência senão, como defendera Quine, na sua periferia, visto que a totalidade da teoria, todos os seus axiomas e proposições que fornecem a unidade de significância da ciência, não pode ser testada a não ser pelo teste de algumas proposições particulares. Esse testes não necessariamente, refutam ou confirmam uma teoria. Cf, Quine, 1975, p.252.

${ }^{7}$ Quine, W, 1975, p.234. Sobre uma crítica do condicionamento da ontologia à epistemologia, defendida por Quine ver: Strawson, P, 2002, p.72.
} 
linearmente - resta-nos saber se isso acarretaria a constituição de uma ciência da complexidade cujo escopo seria capaz de amalgamar os saberes num mosaico de fenômenos ordenados/desordenados. Aqui se trata de outro nível de argumentação que consiste na apresentação das dificuldades epistemológicas quando se estende, como sugere a teoria da complexidade, alguns modelos teóricos complexos para uma ciência da complexidade que subsidiaria, por seu turno, uma epistemologia da complexidade.

As dificuldades que a teoria da complexidade parece negligenciar, figuram no problemático pressuposto de que se pode prover as ciências de um método capaz de fundamentá-las num sistema de filosofia natural - seja esse sistema, segundo a notação de Morin: aberto/complexo, fechado/mecanicista, ordenado/desorganizado, etc. Analisaremos agora essas dificuldades, dividindo-as em quatro argumentos que se seguem embaixo:

1) A normatização do saber sob a unidade do método subscreve uma exigência de unificação das ciências independente das fronteiras que espontaneamente aparecem na pesquisa científica. Nesse sentido, a teoria da complexidade exige do cientista uma atitude deliberadamente voluntarista de abandonar um conjunto de regras de procedimento para protocolar outras independente da natureza do problema em questão: deve-se sempre, argumenta Morin, esquivar-se da especialização do saber (Cf. Morin, 1990, p.16 e 29). Portanto, ela pressupõe - igualmente ao paradigma cartesiano, recorrentemente criticado por Morin - que os cientistas definem o método de uma forma absoluta - anteriormente ao estabelecimento da pesquisa e independente do objeto a ser investigado - separando o modus operandis da ciência do seu respectivo objeto, sugerindo, assim, uma compreensão da ciência descompassada de aplicabilidade ao mundo.

Ainda convém notar que estender a modulação complexa de alguns fenômenos à ciência em geral supõe que as ciências estão orquestradas invariavelmente em função de uma mesma partitura (conceitos e axiomas) e organizadas em virtude dos mesmos interesses. Isto é, a teoria da complexidade aponta para uma rejeição da especificidade de cada ciência, impetrando, porquanto, preceitos de procedimento metodológico universais e adaptáveis a todos os contextos em que se lida com o real: o que quando não se revela falso - considerando que parte substancial das ciências forma seu método em conformidade com as suas dificuldades internas que são introduzidas por suas experiências específicas, do mesmo modo que simultaneamente constrói as condições para experiência em conformidade 
com seu método - parece estéril porque conciliador de uma teoria de afirmações gerais, improficuamente versátil e alheia às idiossincrasias de cada ciência, com as ciências particulares; para as quais generalizações precipitadas são geralmente irrelevantes à solução de seus enigmas específicos.

2) Ademais, a teoria da complexidade toma lacunas teóricas da ciência, como a passagem da disposição das partículas físicas que compõem o universo para as moléculas responsáveis pela constituição do seres vivos, como argumentos para se instituir uma ciência da complexidade, dada a ineficácia do modele científico tradicional em explicar essa passagem. No entanto, a teoria ventilada por Morin não oferece, através desta suposta ciência da complexidade, um único subsídio teórico capaz de indicar alguma explicação exeqüível experimentalmente daquela passagem. Encontramos na teoria da complexidade apenas neologismos dificilmente palatáveis via observação porque prognosticam uma unificação das ciências sem apresentar, contudo, os meandros e as bases que financiariam uma ciência unificada: seus algoritmos e axiomas.

3) Deve-se notar ainda que ao evocar a "quebra" do espaço e tempo absolutos newtonianos, introduzida pela teoria da relatividade, como subterfúgio para a edificação de uma ciência da complexidade - blindada em relação às posturas absolutas - Morin esquece que a teoria da relatividade, como qualquer outra teoria, também guarda suas certezas inegociáveis, entre elas; a velocidade da luz constante (Morin, op. cit. 2003, p.23). Subseqüente a essas considerações, não podemos deixar de perceber que o fato da ciência operar com a incerteza - hipóteses que são a priori indemonstráveis ou fenômenos que não podem ser compreendidos senão de forma probabilística 8 - não autoriza que se depreenda de tal fato contingente, restrito a certos domínios do saber, uma ciência da incerteza cuja conseqüência seria absolutização do caos como resposta à racionalidade cartesiana. Ao contrário, o comportamento aleatório e incerto de alguns fenômenos que certo modelos da ciência contemporânea preconizam, são objetos estritamente equacionáveis como o eram aqueles da física de Newton. Portanto determináveis, ainda que não linearmente.

4) Enfim, estender a fortiori o teorema de Gödel, como defende Morin, para qualquer sistema, sob a alegação que a incerteza faz, ou melhor, deveria fazer parte de todos os sistemas teóricos é estabelecer um juízo a

\footnotetext{
${ }^{8}$ Mesmo Descartes empregou, por demais, hipóteses falsas. Ver: Andrade, 2006, p.251-254
} 
priori sobre a experiência - válido para todas as ciências empíricas - em função de um raciocínio indutivo ${ }^{9}$. Diante da confusão entre a passagem de uma prova formal, cuja validade restringe-se à sistemas formais finitos, para uma assertiva referente à constituição da ciência empírica - considerando que essa última é compostas por sistema de infinitas possibilidades porque as revisões na sua consistência interna lhe constituem enquanto saber - a falácia indutiva dessa argumentação de Morin termina sendo o seu erro menos grave $^{10}$. Ora, ao evocar uma generalização do teorema de Gödel para as ciências, Morin inscreve sua argumentação no âmbito fortemente especulativo que elide uma discussão sobre o eventual parentesco da matemática com as demais ciências sob a obscura alegação que se deve subverter os alicerces das ciências a partir dos resultados concernentes à impossibilidade de formalização da matemática. No entanto, o fato da matemática não poder ser formalizável logicamente não a torna menos importante enquanto linguagem científica, não sendo indicativo de nenhuma crise crônica da ciência empírica - talvez nem mesmo seja um indicativo de uma crise da matemática.

Segue-se dessas observações que os alicerces que sustenta a teoria da complexidade não são sólidos porque, via observação, são inexeqüíveis e, por outro lado, via axiomática, não retém argumentos suficientes para livrá-la das aporias da própria tradição que ela pensa criticar.

\section{Considerações finais: a epistemologia sem complexidade.}

Os "erros" que a história da ciência nos ensinam não revelam apenas confusões internas em alguns sistemas teóricos (falta de precisão conceptual, variáveis mal empregadas, desconhecimento de certas propriedades da matéria, etc.), mas sublevam também os caminhos que tornam a atividade científica mais tortuosa, difícil. Dentre esses caminhos, enorme é a confusão relativa à instauração de uma ciência condicionando-a à ontologia. Lembremos que as inúmeras resistências à teoria de Newton não estavam assentadas em críticas internas ao seus sistema ou a visão pouco abrangente

\footnotetext{
9 "O teorema de Gödel, aparentemente limitado à lógica matemática, vale a fortiori para qualquer sistema teórico: ele demonstra que num sistema formalizado está pelo menos uma proposta que é irresolúvel: essa irresolubilidade abre brecha no sistema, que então se torna incerto". Morin, 2003, p.68.

${ }^{10}$ A falácia consiste numa generalização precipitada: parte-se de um caso particular da matemática e estende-se a sua conclusão a todos os casos possíveis das ciências empíricas.
} 
de sua física em relação à propriedade ondulatória da luz, mas elas ligavam-se sobretudo à dificuldade de se demonstrar metafisicamente a existência da força. Daí, construir uma epistemologia para corroborar uma certa visão de mundo, quando não aliada à prática científica, geralmente produz teorias pouco férteis (as desastrosas assertivas científicas de Hegel é um dos maiores exemplos da improficuidade de uma razão sem crítica) que se distanciam da realidade justamente por acreditarem - dogmaticamente - estar tão perto dela.

Nessa perspectiva a teoria da complexidade farta em neologismos e adjetivos padece de argumentos, uma vez que esses quando não são um requintamento de pressupostos antigos - a ontologia determina a epistemologia - revela a forma mais ardil do dogmatismo contemporâneo, a saber aquela que acredita que a atividade científica deveria ser normatizada em nome de uma verdade metacientífca, impassível de demonstração. Assim, se a resistência ao anarquismo metodológico de Feyerabend é uma questão que urge ser enfrentada pela epistemologia contemporânea, que ainda pensa ser possível justificar o método científico, operar um método universal (aberto/fechado, ordenado/desordenado, etc.) sem uma ciência que lhe corresponda nem uma epistemologia que lhe fundamente é, conquanto, afastar-se da resposta pela incompreensão da gravidade do problema. 


\section{Referências Bibliográficas}

ANDRADE M. OLIVEIRA, É. Hipótese e experiência na constituição da certeza científica em Descartes. Cadernos de História e Filosofia da Ciência. Campinas: UNICAMP, série 3. v.16. Julh-dez. 2006.

ARISTOTE. Métaphysique. Trad. Tricot, J. Paris: Vrin, 1991.

HUME, D. Investigação sobre o entendimento humano. Trad. Vallandro, L. Coleção os Pensadores. Trad. Baraúna, L. J. São Paulo : Abril Cultural, 1973.

MORIN, E.; LE MOIGNE, J. A inteligência da complexidade. Trad. Flaci, M. São Paulo, Peirópolis, 2000.

MORIN, E. Science avec conscience. Paris : Seuil, 1990. . O método. Trad. Da Silva, M. Porto Alegre: Editora Sulinas, 1998. . Introdução ao pensamento complexo. Lisboa, Piaget, 2003.

QUINE, W. Ontological relativit and other essays. New York: Columbia University Press, 1969.

. Os dois dogmas do empirismo. In Coleção os Pensadores. Trad. Da Silva Lima, M. G. São Paulo: Abril Cultural, 1975.

. Sobre o que há. In Coleção os Pensadores. Trad. Da Silva Lima, M. G. SP. Abril Cultural, 1975.

SELLARS, W. Empiricism and the philosophy of mind. Harvard: Harvard University Press, 1997.

SMITH, P. O Cepticismo de Hume. São Paulo: Loyola, 1995.

E-mail: ericoandrade@hotmail.com

Recebido: dezembro/2007 Aprovado: dezembro/2007 